\title{
SISTEMAS DE INOVAÇÃO E APROPRIABILIDADE TECNOLÓGICA: UMA ANÁLISE PELO PARADIGMA DA INOVAÇÃO ABERTA
}

\author{
Alípio José Souza Silva \\ Thiago Caliari Silva
}

\section{RESUMO}

O desenvolvimento de $\mathrm{P} \& \mathrm{D}$ vem ao longo do tempo demonstrando ser um importante ativo de valor estratégico na criação de barreiras à entrada de novos competidores no mercado. Considerando o arcabouço teórico de sistemas de inovação (SI), a apropriabilidade tecnológica é um importante determinante da capacidade inovativa das empresas e por isso, através de uma revisão bibliográfica, procuramos realizar uma discussão teórica que contribuísse para o debate na literatura da inovação aberta dentro da revisão dos conceitos presentes nos sistemas nacionais de inovação. Pode-se verificar que a inovação aberta apresenta-se como uma estratégia interessante de compartilhamento de base científica e tecnológica entre instituições quando a inovação tem como características a sequencialidade e a complementariedade. Nesse caso, a imitação torna-se um elemento estratégico da mudança tecnológica, elevando a "biodiversidade" da tecnologia e melhorando as perspectivas para a inovação futura. Principalmente em firmas focadas em atividades de alta tecnologia a inovação aberta tem se tornado uma ferramenta relevante na busca da competitividade e de share de mercado.

\section{Palavras-chave: Inovação Aberta, Sistemas de Inovação, Apropriabilidade tecnológica.}

\begin{abstract}
The development of R\&D has proven to be an important asset of strategic value in creating entry barriers for new competitors in the market. Considering the theoretical framework of innovation systems (IS), technology appropriability is an important determinant of the innovative capacity of the environment. Therefore, through a literature review, we seek to carry out a theoretical discussion to contribute to the debate regarding open innovation in the review of present concepts in national innovation systems. It can be seen that open innovation is presented as an interesting strategy of scientific and technological base sharing between institutions where innovation has the features of sequentially and complementarity. In this case, imitation becomes a strategic element of technological change, raising the "biodiversity" of technology and improving the prospects for future innovation. Mainly in industries focused on high-tech activities, the open innovation strategy has become an relevant tool in the pursuit of competitiveness and market share.
\end{abstract}

Keywords: Open Innovation, Innovation System, Technological Appropriability

Área ABEIN: Área 6

Classificação JEL: O30 


\section{Introdução}

O desenvolvimento de $\mathrm{P} \& \mathrm{D}$ vem ao longo do tempo demonstrando ser um importante ativo de valor estratégico na criação de barreiras de entrada de novos competidores no mercado. Nessa perspectiva, surgiram diferentes processos de condução de $\mathrm{P} \& \mathrm{D}$, salientando a importância de atores externos (fornecedores, spinoffs, PMEs e etc) como fontes que levem a criação de novos produtos de acordo com as diferentes realidades setoriais.

Podemos observar nos século XIX, por exemplo, o surgimento de uma inovação institucional do departamento de $P \& D$ industrial interno no processo de pesquisa por novos produtos (BEER apud FREEMAN, 1995), com o desenvolvimento de uma indústria com bases sistemáticas, em especial a indústria química, assim como pode ser visto nas indústrias BASF, Bayer dentre outras.

Contudo, no final do século XX surgiam fatos que começavam a corroer a capacidade de inovação fechada nos Estados Unidos como a crescente mobilidade entre os conhecimentos dos trabalhadores, aumentando a dificuldade de controle da propriedade de ideias e experiências por parte das indústrias.

Com as inovações, surgiram novas possibilidades para os engenheiros e cientistas além da tradicionalmente ancorada, ou seja, as inovações permitiram a descentralização do processo de criação de novos produtos através de investidores que não eram proprietários das grandes empresas e viam a possibilidade de grandes ganhos, surgindo o paradigma da inovação aberta (ENKEL, GASSMANN E CHESBROUGH, 2009). Segundo esse novo paradigma, os investimentos realizados exigem um equilíbrio entre a inovação aberta e fechada de modo que a empresa consiga obter vantagem competitiva, criar produtos de valor e garantir a propriedade intelectual dos seus principais produtos.

Sendo assim, o presente trabalho pretende explorar as congruências do entendimento do processo de inovação aberta, considerando-o como uma visão teórica particular e inscrita dentro do conceito de Sistema de Inovação (SI), no qual a apropriabilidade tecnológica é vista de maneira diferente, considerando a distinção do teor inovativo (inovações sequenciais e complementares, dentre outros).

Para tal propósito, o presente estudo foi estruturado em quatro partes, sendo o primeiro esta introdução. O segundo aborda os fundamentos teóricos sobre o processo de construção da pesquisa e desenvolvimento (P\&D). O terceiro faz uma rápida discussão de literatura sobre os Sistemas Nacionais de Inovação (SNI). O quarto apresenta os principais fundamentos teóricos que embasam este trabalho, presentes na revisão de literatura sobre o paradigma da inovação aberta. O quinto realiza uma análise comparativa com as congruências entre a inovação aberta e os sistemas de inovação. E por fim, o sexto apresenta as considerações finais do estudo.

\section{O Processo de Construção de Pesquisa \& Desenvolvimento}

Alguns relatos históricos sugerem que as atividades iniciais de pesquisa e desenvolvimento (P\&D) cresceram pela necessidade da manutenção e melhoria das atividades de produção por muitas indústrias (CHANDLER, 1990 apud. 
CHESBROUGH, 2006) e como tais atividades eram únicas para cada firma, os investimentos em P\&D também eram muito específicos.

Segundo Freeman e Soete (2008), a expansão da departamentalização interna no seio da empresa e de instituições especializadas em P\&D foi talvez a mais importante mudança econômica e social para a produção do século XX, sendo que atualmente os trabalhos de pesquisa e desenvolvimento realizados em laboratórios especializados tiveram papel fundamental na elevação do progresso tecnológico.

A partir da base tecnológica criada pela $P \& D$ interna, as firmas naturalmente se posicionaram para explorar os conhecimentos acumulados para o desenvolvimento de novos produtos, aumentando suas economias de escala e escopo. Em muitas indústrias com larga escala as empresas passaram a dedicar-se de forma específica à função de $P \& D$, criando barreiras de entrada através de economias de escala e de custos (CHESBROUGH, 2006).

Os benefícios de escala e escopo da P\&D interna ocorrem por um aumento vertical integrado dos modelos de inovação onde grandes empresas focavam em suas atividades de $P \& D$, permitindo a comercialização através do desenvolvimento interno, manufatura e distribuição de processos. Assim, o desenvolvimento de $\mathrm{P} \& \mathrm{D}$ vem ao longo do tempo demonstrando ser um importante ativo de valor estratégico na criação de barreiras de entrada de novos competidores no mercado.

Esse é o padrão de inovação conhecido como modelo linear, estabelecido por Vandnevar Bush em 1945 e que compreende a mudança técnica como uma sequência de estágios, em que novos conhecimentos derivados da pesquisa científica levariam a processos de invenção que sucedidos por atividades de pesquisa aplicada e desenvolvimento tecnológico criariam, ao final da cadeia, uma introdução de processos e produtos comercializáveis. Ou seja, a aplicação do conhecimento científico na empresa para descobrir novos processos e produtos (CONDE E ARAUJO-JORGE, 2003).

Em contraponto a essa perspectiva de inovação no modelo linear, após a década de 1950 houve uma significativa evolução nas pesquisas sobre inovação, demonstrando que muitos fatores além da $\mathrm{P} \& \mathrm{D}$ são responsáveis pelo sucesso no processo de inovação. Contudo as dificuldades práticas de incorporação desses fatores nas comparações internacionais ainda eram muito grandes (FREEMAN, 1995).

Algumas contribuições dessa nova literatura dos autores schumpeterianosinstitucionalistas, além dos já apresentados anteriormente, como o modelo KlineRosenberg desenvolvido em 1986 e o modelos de Aoki desenvolvido em 1988, de modo geral enfatizam que existem diferentes processos de condução de $\mathrm{P} \& \mathrm{D}$, sendo que o papel da inovação vai muito além dos conhecimentos derivados da pesquisa científica, salientando a importância da ligação entre as diferentes atividades de pesquisa e as atividades industriais e comerciais, a coordenação interna, as estruturas informacionais e os atores externos (fornecedores, spin-offs, PMEs e etc) (SILVA E DACORSO, 2013; KUPFER E HASENCLEVER, 2013).

\section{Sistemas Nacionais de Inovação (SNI)}

É importante observarmos o fato de que muitos dos melhoramentos nos produtos e serviços surgiram diretamente da interação com o mercado e com firmas relacionadas, tais como fornecedores de materiais e serviços. A inovação formal costumava exercer uma contribuição decisiva nas inovações radicais, mas não era possível ignorar as várias 
outras influências dentro do processo de mudança técnicas no nível das indústrias (FREEMAN, 1995).

A partir do instante em que as maiores tecnologias 'genéricas' (biotecnologia, tecnologia de novos materiais e tecnologia informacional) se difundem no mercado mundial a partir das décadas de 1970/80, os aspectos estruturais da inovação assumem cada vez mais um papel de destaque, tornando-se cada vez mais consenso que o sucesso das atividades inovativas, os ganhos de produtividade e suas taxas de difusão dependiam de uma ampla variedade de outras atuações, assim como das P\&D formais (FREEMAN, 1995; FREEMAN E SOETE, 2008).

Podemos observar que essa observação abre espaço para o entendimento do processo inovativo como dependente de uma ampla variedade de atores institucionais e relacionamentos, ligados diretamente ao conceito de Sistemas Nacionais de Inovação (FREEMAN, 1995).

Em outros termos, as estruturas industriais, as tecnologias e as instituições de suporte se interdependem (ALTENBURG, 2008). Estes fatores explicam o porquê de o conhecimento tecnológico ser profundamente enraizado nas instituições específicas das sociedades e por isso seu conteúdo e disponibilidade possuem uma grande variabilidade entre sociedades, mesmo que a dotação de fatores seja semelhante.

Na vida econômica, as instituições tem uma importante função de reduzir os custos de transação. Em nosso caso, em uma economia competitiva e moderna as instituições-chave são direcionadas para um melhor funcionamento do mercado. $\mathrm{O}$ mercado é o principal agente construtor da competição como processo chave da inovação, por isso, políticas ${ }^{1}$ de promoção à competição são centrais no crescimento da produtividade de um país. Isso inclui leis contra o monopólio, abertura de mercado e medidas de incentivo a entrada e saída de firmas (ALTENBURG, 2008).

Nas inovações radicais, por exemplo, diferentemente das inovações incrementais ${ }^{2}$, a importância de uma variedade institucional e do aprendizado localizado são ainda maiores, uma vez que uma teoria de mudança técnica que ignore a interdependência entre inovação técnica e inovação organizacional não é mais útil que uma teoria econômica na qual ignora a interpendência de preços e quantidades em uma economia mundial (LUNDVALL, 2007).

Dado à importância de inovações radicais nos sistemas nacionais de inovação, reconhecemos que o nível de financiamento da $\mathrm{P} \& \mathrm{D}$ é influenciado pelas políticas nacionais (como, por exemplo, políticas macroeconômicas) e também pelo comportamento das instituições nacionais (como, por exemplo, o mercado de capitais, agências de fomento e sistemas de governança corporativa).

Observamos o aumento do padrão e da complexidade da competição entre as empresas exigindo das organizações uma capacidade maior de gerenciamento de incertezas e acompanhamento das rápidas mudanças no mercado, transitando para uma dinâmica em torno do domínio do conhecimento, que por vezes, é encontrado fora dos limites da firma.

\footnotetext{
${ }^{1}$ A elaboração de politicas apropriadas aos países em desenvolvimento é essencial para a construção de uma sólida aprendizagem tecnológica com importante desenvolvimento do sistema nacional de inovação.

2 No caso de inovação incremental em economias abertas, a forma com que se dirige em torno da padronização é limitada, sendo a proximidade geográfica e cultural dos usuários avançados e a ligação o relacionamento dos produtores-usuários um importante recurso para a vantagem comparativa e diversificação na inovação (LUNDVALL, 2007).
} 
Essa necessidade de gerenciamento de incertezas se dá pelo fato de que a socialização de alguns dos riscos e incertezas decorrentes dentro da inovação técnica é difícil de ser evitada por conta de algumas características inerentes ao processo como: a) as externalidades, b) pressões da competição mundial e c) dos fatores de escala da P\&D em conjunto com consequências adversas do "laissez-innover" (FREEMAN E SOETE, 2008).

Em decorrência desses fatores, e dada a importância dos trabalhos de pesquisa e desenvolvimento realizados em laboratórios especializados na elevação do progresso tecnológico (FREEMAN E SOETE, 2008), uma nova literatura emergiu para tentar entender as relações entre $P \& D$, os sistemas regionais de inovação e a geração de novos processos produtivos em que o acesso à informação e à criação de novos produtos se encontram altamente globalizados e além dos laboratórios internos das grandes empresas, o que denominamos de paradigma da inovação aberta (CHESBROUGH, 2003).

\section{O Paradigma da Inovação Aberta}

Vários modelos vêm sendo criados para explicar como as firmas podem explorar os conhecimentos externos, mas o mais simples de todos se resume a imitação de um competidor. A pesquisa com consumidores que lidarão com usuários finais também podem fornecer ideias à firma sobre como descobrir, desenvolver e aperfeiçoar suas inovações (VON HIPPEL, 1988 apud. CHESBROUGH, 2006).

A literatura tradicional, baseada em um padrão econômico racional e focada na proteção de inventores por patentes diz que, a menos que o competidor seja impedido de imitar uma invenção, o inventor pode não colher lucro suficiente para cobrir esse custo (BESSEN E MASKIN, 1999).

A indústria de software dos Estados Unidos, por exemplo, foi submetida durante os anos de 1980 e 1990 a importantes experiências de fortalecimento das patentes de programas de computadores e longe de desencadear uma onda de nova atividade inovadora, as firmas que adquiriram muitas dessas patentes reduziram seus gastos de P\&D em relação às vendas (BESSEN E MASKIN, 1999).

Nesse caso, as evidências sugerem que a proteção por patentes não levou a um resultado ótimo, porque para alguns setores específicos, como a indústria de software ou computadores, a teoria sugere que a imitação deve promover a inovação e que patentes fortes (patentes com longa duração) podem, na verdade, inibi-la (BESSEN E MASKIN, 1999).

Assim, caso a proteção da propriedade intelectual fosse mais limitada em indústrias, as empresas inovadoras poderiam desenvolver de forma mais efetiva o processo de imitação ${ }^{3}$, ainda que reduzam o lucro em sua descoberta atual elas aumentam a probabilidade de inovações ${ }^{4}$ posteriores, e consequentemente a melhoria de lucro futuro.

\footnotetext{
3 Bessen e Maskin (1999) mostram que existem indústrias em que a inovação é ao mesmo tempo sequencial e complementar. Por sequencial, entende-se que a cada invenção sucessiva é construída por uma invenção anterior e complementar significa que cada inovador potencial toma uma linha de pesquisa diferente, aumentando assim à probabilidade geral que um objetivo específico seja alcançado dentro de um determinado tempo, logo a imitação pode ser socialmente desejável em indústrias de inovação sequencial e complementar porque ajuda o imitador a desenvolver novas invenções.

${ }^{4}$ Bessen e Maskin (1999) não descartam a ideia de que ainda em um ambiente sequencial, alguma forma de proteção é essencial para promover a inovação caso não haja nenhum custo para a entrada e não haja
} 
Esse fato ocorre porque quando a inovação é sequencial e complementar, a imitação torna-se um incentivo à inovação já que os diferentes padrões de $\mathrm{P} \& \mathrm{D}$ por trás dos produtos permitem complementaridades inovativas, ou seja, a imitação tende a alavancar a "biodiversidade" da tecnologia, melhorando as perspectivas para a inovação futura e a empresa pode ser capaz de produzir valor com as inovações através de licenciamento, estimulando a produção de mais inovações (BESSEN E MASKIN, 1999; TEECE, 1986).

Além disso, a complementaridade entre as firmas ${ }^{5}$ no cenário sequencial cresce naturalmente quando algumas, mas não todas, as informações técnicas necessárias para a inovação se difundem livremente ou a baixo custo.

Já em um modelo estático ${ }^{6}$ (não sequencial), patentes ${ }^{7}$ são melhores que a não existência delas desde que o limite superior da distribuição de valores de inovação seja suficientemente consistente e o bem-estar esperado com a proteção das patentes exceda o caso de sua não proteção, em resumo, a concorrência de forma explícita diminui a recompensa de um possível inventor (BESSEN E MASKIN, 1999).

No caso de indústrias de alta tecnologia, uma vez que tais firmas possuem a habilidade de gerar receitas positivas (ainda que possivelmente reduzidas) quando realizado o processo de imitação. Isso significa dizer que as patentes podem, no caso dessas indústrias, reduzir o bem-estar, já que o bloqueio da imitação poderá interferir em inovações futuras (BESSEN E MASKIN, 1999).

Por isso, dependendo da atividade setorial, a sociedade e alguns inventores ficarão em melhores condições sem tais proteções. No caso da Inovação Aberta, observamos essas evidências partindo da análise de indústrias de "alta tecnologia". Isso implica no fato de que em firmas maiores, com um mercado mais voltado a atividades de alta tecnologia, como na produção de semicondutores, a proteção da propriedade intelectual é direta, a inovação aberta torna-se ferramenta de governança essencial para garantir a competitividade e a conquista robusta de uma parte do mercado (HUIZINGH E KRE, 2011; FELIN E ZENGER, 2014).

Isso ocorre porque a inovação aberta afeta as habilidades da firma de gerar e capturar as rendas da economia que acompanham a vantagem competitiva que vem do controle da propriedade intelectual, subjacentes às inovações (REED, STORRUDBARNES E JESSUP, 2012).

Para Reed, Storrud-Barnes e Jessup (2012), a Inovação aberta permite ganhos monopolísticos de economias de escala ${ }^{8}$, curva de efeitos de experiência e requisição de capital. Como observam Huizingh e Kre (2011), a inovação aberta se tornou um termo que engloba, conecta e integra uma série de atividades já existentes, assim existem

\footnotetext{
limite para a rapidez de como a imitação pode ocorrer. Nesse caso, os imitadores poderiam copiar imediatamente, sempre que uma nova descoberta for feita, levando as receitas do inventor para zero. Porém, eles assumem que a entrada requer investimento em capital especializado, seja capital humano ou não.

${ }^{5}$ Isso ocorre porque em um cenário típico, o sucesso comercial de um produto inovador mostra informações parciais que é útil para aspirantes a inventores (talvez porque ele facilita a engenharia reversa), que, em seguida, aplica a sua própria experiência particular (BESSEN E MASKIN, 1999).

${ }^{6}$ Como descrito na proposição 1 de Bessen e Maskin (1999), "Em um modelo estático, o nível de equilíbrio de investimento em P\&D sem patentes é menor ou igual ao ótimo social. Por contraste, o nível de equilíbrio do investimento em P\&D com proteção a patente é maior que o ótimo social” (p.14).

${ }^{7}$ Vale lembrarmos que apesar das patentes incentivam imitadores a investir em inovação, elas também criam um risco de sobreinvestimento em P\&D (BESSEN E MASKIN, 1999).

${ }^{8}$ Sandroni (1994) define economia de escala como "a produção de bens em larga escala, com vistas a uma considerável redução nos custos, resultando na racionalização intensiva da atividade produtiva”.
} 
diferentes práticas da inovação aberta (natureza multidimensional) e estas podem ser ligadas a diferentes matrizes que distinguirão as diferentes formas de se inovar. Os autores constroem a ideia de que existem diferentes práticas da inovação aberta (natureza multidimensional) e estas podem ser ligadas à diferentes matrizes que distinguirão as diferentes formas de se inova e um excesso de inovação aberta pode afetar negativamente no desempenho da empresa.

Deve-se observar que o contexto pode definir a relação entre um bom desempenho da firma, implicando que as práticas de inovação aberta são mais efetivas em alguns contextos do que em outros como, por exemplo, em estratégias de lucratividade, onde a proteção da propriedade intelectual é direta (HUIZINGH E KRE, 2011).

Nelson e Winter (1982), por exemplo, procuraram modelar a decisão da firma por procurar uma nova tecnologia de fora no processo de criação da organização, Cohen e Levinthal $(1989,1990)$ demonstraram os dois lados da P\&D (o lado de dentro de fora da firma), além da importância do investimento na pesquisa interna objetivando utilizar tecnologias externas, o que eles denominaram "capacidade absortiva”.

Se as empresas não desenvolvem capacidades absortivas suficientes por si próprias, elas devem se utilizar de alianças estratégicas objetivando ganhar tais conhecimentos, utilizando recursos complementares para exploração desse conhecimento. Essa abordagem de aliança é particularmente comum em indústrias com tecnologias intensivas como as de biotecnologia (POWELL, KOPUT E SMITHDOERR, 1996 apud CHESBROUGH, 2006).

Nesse novo modelo de Inovação Aberta, as firmas comercializam ideias externas pela implantação de caminhos externos no mercado $^{9}$, portanto, as companhias olham as oportunidades de forma diferente, incorporando a capacidade de resgatar "falsos negativos" (projetos que inicialmente pareciam não ter capacidade, mas se tornam de surpreendentes valores) e reavaliando as ideias não aproveitadas que requerem um novo tipo de distribuição desconhecida de recursos, bens e posições, permitindo a circulação e uso dessas ideias em outras empresas nas quais essas pesquisas possam gerar um novo produto (CHESBROUGH, 2003).

Dahlander e Gann (2010) procuram esclarecer que a inovação aberta pode ser vista como um exemplo de como as firmas tomam decisões entre desenvolver as inovações internamente ou parcerias com atores externos.

Logo os investimentos realizados exigem um equilíbrio entre a inovação aberta e fechada de modo que a empresa consiga obter vantagem competitiva, criar produtos de valor e garantir a propriedade intelectual dos seus principais produtos (CHESBROUGH, 2012).

Laursen e Salter (2014) tentam expor, a partir da literatura emergente em inovação aberta, como as decisões das firmas por abrir para diferentes atores externos são relacionados às escolhas que eles fazem sobre sua estratégia de apropriabilidade ${ }^{10}$.

\footnotetext{
9 O novo paradigma criado por Chesbrough (2003) expõe que o conhecimento externo além de desempenhar um papel útil, também suplementa na teorização prévia sobre inovação, jogando com as regras iguais ao que é assegurado pelo conhecimento interno em concepções anteriores. Observa-se ainda quatro recursos externos de conhecimento útil ajudam nesse processo de identificação: 1) universidades, governos e laboratórios privados; 2) ofertantes e consumidores; 3) competidores e 4) outras nações (VON HIPPEL, 1988 apud. CHESBROUGH, 2006).

${ }^{10}$ A apropriabilidade pode ser entendida como a abordagem decidida pela firma, para proteger os seus conhecimentos contra uma possível tentativa de cópia ou apropriação dos retornos de suas atividades inovadoras. É importante enfatizarmos o fato de que a aplicação de mecanismos de proteção excessivamente restritivos pode reduzir o interesse dos gestores das empresas em colaborar, ou ainda
} 
O que ocorre aqui é que em um modelo de Inovação Aberta, a propriedade intelectual representa uma nova classe de ativos que podem ser entregues como receitas adicionais ao atual modelo de negócios, além de permitir criar novas entradas, dentro de um negócio, gerando novos modelos de negócios (VANHAVERBEKE, VAN DE VRANDE E CHESBROUGH, 2008; CHESBROUGH, 2006).

Esses fatores são importantes porque uma firma que é focada internamente (com uma abordagem de inovação fechada) fica sujeita a perder um número de oportunidades porque muitas cairão fora dos negócios correntes ou precisaram se combinar com tecnologias externas que destravam seu potencial, podendo ser doloroso para as corporações que fizeram um investimento substancial em pesquisas ao longo prazo, somente para descobrir mais tarde que alguns desses projetos abandonados se tornaram de grande valor comercial (WEST et al., 2014).

Roper, Vahter e Love (2013) utilizando-se da análise de dados em painel com base em modelos de regressão de variáveis instrumentais da indústria de transformação irlandesa durante o período que compreende 1994 a 2008, sugerem que existe uma evidência positiva entre a existência de externalidades na abertura da inovação, fornecendo uma justificativa plausível para a intervenção pública de forma a incentivar o aumento de estratégias de inovação aberta, maximizando o benefício social da abertura. Os autores mostram ainda que uma competição mais intensa, através das inovações abertas, pode aumentar o incentivo ao investimento em inovação aberta já na entrada da firma, resultando em uma melhoria de longo prazo na produtividade da inovação ${ }^{11}$.

Dessa forma, se torna essencial entendermos a conceituação e o funcionamento do modelo de negócios no processo de inovação aberta.

\subsection{O modelo de negócios na Inovação Aberta}

A construção de um modelo de negócios robusto permite a empresa encontrar de forma mais efetiva as oportunidades de mercado, criando a possibilidade de competir a partir da reinvenção do que já existe no mercado.

A inovação aberta utiliza-se de modelos de negócios que procuram definir as arquiteturas e sistemas em que as ideias internas e externas possam criar valor, ao conseguir definir mecanismos internos para reivindicar uma parcela desse valor. É essencial para o processo de Inovação Aberta que as ideias internas também possam ser tomadas pelos canais de mercado externo, fora do atual negócio da firma, para gerar valor adicional, ou seja, o processo de pesquisa e desenvolvimento é tratado como um sistema aberto (ENKEL, GASSMANN E CHESBROUGH, 2009).

Nas invenções da Xerox PARC, por exemplo, o crescimento do modelo de negócios foi mediado dentre as entradas internas e os benefícios econômicos da tecnologia, estruturando como as firmas criaram e capturaram valor de um mercado específico (CHESBROUGH E ROSENBLOOM, 2002).

afastar os atores externos no sistema de inovação, logo a estratégia de apropriabilidade da firma está estreitamente ligada ao nível de abertura da empresa.

${ }^{11}$ É importante enfatizar o fato de que a força em que este tipo de competição exercerá depende da distância em que a firma particular estará dos seus competidores em termos de desempenho da inovação e nível de tecnologia/conhecimento. 
As empresas que praticam as competências do modelo de inovação aberta aumentam suas chances de entrar em outros mercados por meio da atuação em conjunto com outra firma; podendo ter acesso ao portfólio de tecnologias de outras companhias, disseminando tecnologia própria para outras empresas, o que permite criar um potencial de lucro com essa tecnologia que até então era obsoleta em seu portfólio, além de não infrigirem as lei de propriedade intelectual (PI), já que a informação passa a ser compartilhada, podendo ainda desenvolver atividades compartilhadas de P\&D, oportunizando a conquista de liderança tecnológica (CHESBROUGH, 2006).

Podemos observar, por exemplo, o caso da IBM que repensou em toda a abordagem de gerencialmente de propriedade intelectual, especialmente nas tecnologias e patentes. Mudando de uma abordagem defensiva (focado na proteção de PI) para uma abordagem efetiva (focado no licenciamento de PI para terceiros), a companhia foi capaz de gerar significantes novas receitas (CHESBROUGH, 2013).

A inovação aberta potencializa o potencial de criação de novos negócios e reduz os riscos, aumentando o aprendizado em vários espaços de companhias inovadoras. Nesse caso, as firmas têm a possibilidade de desenvolver novas competências em ordem migrar através de mais tecnologias atrativas e aplicações.

Contudo vale lembrar que as vantagens não vêm automaticamente. As companhias devem desenvolver novas rotinas, habilidades e estratégias (VANHAKERBEKE, VAN DE BRANDE \& CHESBROUGH, 2008) ${ }^{12}$. Em sua essência a inovação aberta assume que o conhecimento útil é globalmente distribuído, e que as organizações de $P \& D$ podem identificar, e conectar-se, e alavancar-se a fontes de conhecimentos externos como um processo de inovação.

Para que se possa realizar a escolha de qual caminho tomar na P\&D interna, disseminação do aprendizado gerado nesse processo interno, além da busca e abertura para tecnologias e ideias e soluções externas até a geração de um novo processo, produto ou criação de nova tecnologia, devemos entender em que contexto se insere o paradigma da inovação aberta dentro dessas etapas e como se realiza esse processo em cada uma dessas fases.

\subsection{O processo de inovação aberta}

Existem dentro do processo de inovação aberta dois tipos de processos iniciais até a geração da inovação: a entrada de inovação aberta (inbound open innovation) e a saída de inovação aberta (outbound open innovation). A entrada de inovação aberta, por exemplo, refere-se ao uso interno de conhecimento externo enquanto o processo de saída da inovação aberta refere-se à exploração do conhecimento interno, referindo-se a três processos de conhecimento: a exploração, a manutenção e a retenção que pode ser utilizada dentro ou fora da empresa (HUIZINGH E KRE, 2011).

A grande diferença da inovação aberta se insere exatamente no processo de saída, uma vez que ela permite a busca de fluxos de ideias externas para resolução de problemas internos, e em troca, oferece o fluxo de ideias internas que não utilizados dentro da empresa para resolução de problemas externos, como será exposto de forma mais contundente nos próximos parágrafos.

Segundo o processo de inovação a partir do modelo de inovação fechada, os projetos de pesquisa são lançados da base científica e tecnológica da firma. Seu

\footnotetext{
${ }^{12}$ Segundo os autores, "Where there is a wealth of information, there is a poverty of attention".
} 
progresso através do processo, e alguns projetos são encerrados, enquanto outros são selecionados para continuação de seu desenvolvimento e um subconjunto desses são escolhidos para que sejam encaminhados para o mercado.

Esse processo é denominado processo "fechado" porque projetos somente podem entrar em um caminho, no começo, e somente podem sair por um caminho, indo para o mercado. Os laboratórios Bell da AT\&T são um exemplo desse modelo, com notáveis conquistas em muitas pesquisas, mas com uma notória cultura focada para dentro (CHESBROUGH, 2006).

Em um modelo de Inovação Aberta, os projetos podem ser desenvolvidos por tecnologias de recursos internos ou externos, e uma nova tecnologia pode se inserir dentro de um processo em vários estágios.

Quando as firmas saem para absorver conhecimento externo, tem como objetivo o desenvolvimento interno da manufatura e das vendas. No paradigma da Inovação Aberta, abrir os fluxos de saída de tecnologias permitem as tecnologias que estejam em falta a serem preenchidas em sua busca de mercado interno através do padrão externo ${ }^{13}$.

No modelo de Inovação Aberta, acredita-se que o conhecimento útil está universalmente distribuído, e geralmente em alta qualidade ${ }^{14}$ e por isso, torna-se fundamental avaliar a qualidade da aplicabilidade desses conhecimentos com 0 desenvolvimento de métricas específicas.

O grande interesse prático predomina no mercado uma vez que os gestores observaram que esse novo paradigma leva a uma redução de custo considerável porque muitas firmas estão na posição de usar a tecnologia ao invés de criá-la.

Segundo Vanhaebrbeke, Van de Vrande e Chesbrough (2008), as firmas inovadoras têm de aprender novas rotinas e habilidades toda à "opção real” de potencial das práticas de inovação aberta, cada negócio matura depois de um tempo, por isso as firmas devem sempre olhar para novas oportunidades de negócios já que estender a vida útil de seus produtos deve ser uma solução de curto prazo.

\subsection{O paradigma da inovação aberta como alternativa competitiva}

A evolução do mercado e das necessidades dos clientes junto ao aumento da competição global trouxeram uma necessidade crescente de inovação por parte de

${ }^{13} \mathrm{O}$ negócio interno da firma agora é complementado com canais externos de mercado para novas tecnologias, fornecendo evidências de emergência ou negligência técnica das oportunidades de mercado (de certa forma, sendo uma segunda opinião), constituindo uma forma de gerenciar os projetos de P\&D "falsos negativos".

\footnotetext{
${ }^{14}$ A respeito da melhor forma de se utilizar o conhecimento, cabe aqui a exposição de Hayek (1945). Como expõe Hayek (1945), o problema econômico da sociedade não é meramente de como alocar os recursos dados, isso é um problema da utilização do conhecimento não dado a todos em sua totalidade. Tanto teoria econômica e política econômica têm suas origens em comum em um equívoco sobre a natureza dos problemas econômicos da sociedade. Esse equívoco, por sua vez ocorre devido a um erro de transferência para o fenômeno social dos hábitos de pensamento que nós temos desenvolvido ao lidar com os fenômenos da natureza. Os vários caminhos no qual o conhecimento de cada pessoa baseia seus planos é comunicado a elas é um problema crucial para qualquer teoria que explique o processo econômico. E o problema de qual é o melhor caminho para utilizar o conhecimento inicialmente dispersado entre todas as pessoas é de certa forma um dos problemas principais de política econômica, ou de desenho de um sistema econômico eficiente. Não podemos esperar que os problemas da sociedade sejam comunicados todos os conhecimentos para uma entidade central, depois integrando todo o conhecimento para resolução. Nós precisamos resolver isso por alguma forma de descentralização.
} 
algumas realidades setorias, como é o caso das empresas com alto nível de tecnologia (software, computadores, etc) e diante dessas questões, o modelo de inovação aberta surge como nova alternativa competitiva, dada as possibilidades de aprendizado, acesso a tecnologias, conhecimento, posicionamento competitivo e geração de valor.

Por fim, é importante entendermos que ainda é muito cedo para que possamos afirmar que o paradigma da inovação aberta vá fornecer uma contribuição duradoura para a nossa compreensão da inovação, porém podemos afirmar que tal paradigma vem causando grande impacto em nossa compreensão sobre inovação.

A partir dessa perspectiva, muitas das indústrias inovadoras (software, semicondutores, biotecnologia, computadores), nas últimas três décadas, historicamente tem enfraquecido suas políticas de proteção de patentes e buscado soluções externas às suas necessidades e tem com isso, experimentado rápida inovação em seus produtos.

\section{Congruências Teóricas entre Inovação Aberta e Sistemas de Inovação}

Desde 1970, alguns pesquisadores tem entendido e verificado que muitas vezes os recursos para a ideias inovativas vem de fora da firma como Gibbons e Johnston (1974) estudando os recursos de informação para invenções técnicas, Freeman e Soete (2008) em sua pesquisa sobre a indústria química, von Hippel (1976) e o crescimento de usuários na geração de inovações e Allen (1977) com estudo do crescimento da habilidade da firma com a assimilação de conhecimento externo e portanto, os estudos desses autores já reconheciam o surgimento de um novo modelo, ainda que ainda não fosse denominada de Inovação Aberta (mais tarde feita por Chesbrough(2003).

O modelo de Inovação Aberta nasce a partir da análise dos estudos de Freeman (2008) e outros a respeito dos sistemas de inovação, ou seja, a inovação aberta é baseada sob um modelo verticalmente integrado de $P \& D$, logo sendo de certa forma um subproduto do estudos de SNI.

Ainda que se enfatize a importância de sistemas de inovação abertos como formas de desenvolvimento para economias atrasadas, as inovações ainda continuam apresentando um importante conteúdo local específico, por envolverem um conjunto de fatores que vão além dos aspectos unicamente tecnológicos, além de serem também de natureza institucional (NELSON, 2002). Deve-se atentar ao fato de que o desenvolvimento do produto/processo e a difusão do conhecimento ${ }^{15}$ irão depender das características da empresa, ou seja, quanto mais concentrada a empresa, menor a necessidade de aprendizado interativo (DATHEIN E PEREIRA, 2012).

Os dois fenômenos são inicialmente desenvolvidos por um pequeno número de praticantes da inovação, possuindo como foco inicial um grande número de indústrias de alta tecnologia, distinguindo-se apenas sobre o formato em que se escolhem suas ideias. Seja no sistema de inovação como na inovação aberta, vê-se a grande importância da P\&D para a realização do processo de inovação, porém a inovação aberta é adeptas a ideia dos "falsos positivos" (isso é, ideias ruins que inicialmente parecem promissoras), e do resgate de “falsos negativos” (projetos que inicialmente pareciam não ter capacidade, mas se tornam de surpreendentes valores).

\footnotetext{
15 Dathein e Pereira (2012) identificam uma grande relação entre o processo de aprendizado, a rotina e o conhecimento tácito, em que a inovação (entendido aqui por um processo criativo) “(...) é resultado da relação entre compreensão e execução, que conduzem a uma melhor concepção do processo produtivo e/ou organizacional”(p. 13).
} 
A visão da inovação aberta permite que as ideias, a propriedade intelectual e as pessoas circulem livremente tanto dentro como fora da organização, o que induz a empresa na criação de novos produtos e novas capacidades internas (CHESBROUGH; GARMAN, 2009).

No paradigma da Inovação Aberta, abrir os fluxos de saída de tecnologias permite que tecnologias deficitárias ao nível da firma sejam preenchidas em sua busca de mercado interno através do padrão externo constituindo uma importante forma de gerenciar os projetos de $\mathrm{P} \& \mathrm{D}$ "falsos negativos". Em suma, uma vez que se as empresa não desenvolvem capacidades absortivas suficientes por si próprias, elas devem se utilizar de alianças estratégicas objetivando ganhar tais conhecimentos, utilizando recursos complementares para exploração desse conhecimento.

Essa abordagem de aliança é particularmente comum em indústrias com tecnologias intensivas como as de biotecnologia, software, eletrônica, telecomunicações, farmácia e biotecnologia. No software, vemos a Microsoft construindo laboratórios descentralizados de pesquisa ou em universidades objetivando aumentar sua capacidade absortiva do processo de inovação outside-in (POWELL, KOPUT E SMITH-DOERR, 1996 APUD CHESBROUGH, 2006; GASSMANN, ENHEL, CHESBROUGH, 2010).

\section{Considerações Finais}

A evolução da importância da institucionalização das atividades de pesquisa e desenvolvimento para o processo de inovação tecnológica mostra que essas atividades se tornaram uma importante estratégia na criação de barreiras de entrada de novos competidores no mercado em um primeiro momento, contribuindo de forma decisiva nas inovações radicais sem ignorar em um segundo momento, outras influências dentro do processo de mudança técnicas no nível das indústrias. Porém, com o avanço dos processos de P\&D nas décadas de 1970/80, a partir do instante em que setores como o de biotecnologia e tecnologia da informação se apresentam como os novos paradigmas tecnológicos mundiais, a estrutura da inovação começa a assumir uma função diferente no mercado mundial.

Já que a difusão dependia de uma ampla variedade de outras atuações, verificase um aumento nos custos do desenvolvimento dos processos tecnológicos com a redução da necessidade de apropriabilidade tecnológica interna plena e do ciclo de vida dos produtos, exigindo das organizações uma capacidade maior de gerenciamento de incertezas e acompanhamento das rápidas mudanças no mercado.

Em determinados setores, como a indústria de software, a proteção por patentes não elevou o conteúdo inovativo a resultados satisfatórios, visto que a inovação é sequencial e complementar, ou seja, a imitação deve promover a inovação pois tende a alavancar a diversidade tecnológica com o melhoramento da inovação futura, sendo capaz de produzir valor através de licenciamento e estímulo na produção de mais inovações.

Conclui-se, portanto, em firmas com um mercado mais voltado à atividades de alta tecnologia, caracterizada por um desenvolvimento sequencial e complementar (como a produção de software) a inovação aberta torna-se ferramenta essencial na garantia da competitividade e a conquista robusta de uma parte do mercado.

Em suma, deve-se atentar para possíveis congruências no processo de inovação aberta que surge na verdade como uma visão teórica dentro do conceito de sistema nacional de inovação, no qual a apropriabilidade tecnológica é vista de maneira 
diferente visto o teor diferente da inovação (sequencial, complementar, etc), uma vez que todo modelo que surge como novo paradigma da inovação industrial deve contar com o estabelecimento de paradigmas anteriores que os dão suporte (KUHN, 1962; FEYERABEND, 1981 apud. CHESBROUGH, 2006).

\section{REFERÊNCIAS BIBLIOGRÁFICAS}

ALLEN, Thomas J. "Managing the flow of technology: technology transfer and the dissemination of technological information within the R and D organization”. 1977.

ALTENBURG, Tilman. "Building inclusive innovation systems in developing countries-why it is necessary to rethink the policy agenda”. In: Globelics Conference, Mexico City. 2008.

BESSEN, James; MASKIN, Eric. "Sequential innovation, patents, and imitation”. The RAND Journal of Economics, v. 40, n. 4, p. 611-635, 1999.

CHESBROUGH, Henry; ROSENBLOOM, Richard S. "The role of the business model in capturing value from innovation: evidence from Xerox Corporation's technology spin-off companies”. Industrial and corporate change, v. 11, n. 3, p. 529-555, 2002.

CHESBROUGH, Henry W.; GARMAN, Andrew R. How open innovation can help you cope in lean times. Harvard business review, v. 87, n. 12, p. 68-76, 128, 2009.

CHESBROUGH, Henry. The logic of open innovation: managing intellectual property. California Management Review, v. 45, n. 3, p. 33-58, 2003.

CHESBROUGH, Henry. "Open innovation: a new paradigm for understanding industrial innovation”. Open innovation: Researching a new paradigm, p. 1-12, 2006.

CHESBROUGH, Henry. "Business model innovation: it's not just about technology anymore”. Strategy \& leadership, v. 35, n. 6, p. 12-17, 2007.

CHESBROUGH, H. "Why companies should have open business models". MIT Sloan management review, v. 48, n. 2, 2012.

CHESBROUGH, Henry. "Open business models: How to thrive in the new innovation landscape”. Harvard Business Press, 2013.

CONDE, Mariza Velloso Fernandez; ARAÚJO-JORGE, Tania Cremonini de. Modelos e concepções de inovação: a transição de paradigmas, a reforma da C\&T brasileira e as concepções de gestores de uma instituição pública de pesquisa em saúde. Ciência \& 
saúde coletiva, v. 8, n. 3, p. 727-741, 2003.

DAHLANDER, Linus; GANN, David M. “How open is innovation?”. Research policy, v. 39, n. 6, p. 699-709, 2010.

DACORSO, Antônio Luiz Rocha; SILVA, Glessia. Inovação aberta como uma vantagem competitiva para a micro e pequena empresa. 2013.

DATHEIN Ricardo; PEREIRA Adriano José. "Sistema Nacional de Inovações e comportamento inovativo das grandes empresas nacionais e estrangeiras da indústria de transformação brasileira”. Porto Alegre: UFRGS/FCE/DE RI, 2012.

ENKEL, Ellen; GASSMANN, Oliver; CHESBROUGH, Henry. "Open R\&D and open innovation: exploring the phenomenon”. R\&D Management, v. 39, n. 4, p. 311-316, 2009.

FELIN, Teppo; ZENGER, Todd R. "Closed or open innovation? Problem solving and the governance choice”. Research Policy, v. 43, n. 5, p. 914-925, 2014.

FREEMAN, Chris. “The 'National System of Innovation' in historical perspective”. Cambridge Journal of economics, v. 19, n. 1, p. 5-24, 1995.

FREEMAN, Christopher; SOETE, Luc. A Economia da Inovação Industrial. Tradutores: André Luiz Sica de Campos e Janaina Oliveira Pamplona da CostaCampinas,SP: Editora da Unicamp, 2008.

GIBBONS, Michael; JOHNSTON, Ron. "The roles of science in technological innovation”. Research Policy, v. 3, n. 3, p. 220-242, 1974.

HAYEK, Friedrich August. "The use of knowledge in society”. The American economic review, p. 519-530, 1945.

HUIZINGH, Eelko KRE. "Open innovation: State of the art and future perspectives”. Technovation, v. 31, n. 1, p. 2-9, 2011.

KUPFER, David; HASENCLEVER, Lia. Economia industrial: fundamentos teóricos e práticas no Brasil. Editora Campus: Rio de Janeiro, 2 ed., 2013.

LUNDVALL, B-Â. "National Innovation System: analytical focusing device and policy learning tool”. Swedish Institute for Growth Policy Studies- ITPS. Working Paper 4, 2007

NELSON, Richard R. Bringing institutions into evolutionary growth theory.Journal of Evolutionary Economics, v. 12, n. 1-2, p. 17-28, 2002. 
NELSON, Richard R.; SIDNEY, G. Winter. An evolutionary theory of economic change. 1982.

REED, Richard; STORRUD-BARNES, Susan; JESSUP, Len. "How open innovation affects the drivers of competitive advantage: Trading the benefits of IP creation and ownership for free invention”. Management Decision, v. 50, n. 1, p. 58-73, 2012.

ROPER, Stephen; VAHTER, Priit; LOVE, James H. Externalities of openness in innovation. Research policy, v. 42, n. 9, p. 1544-1554, 2013.

SANDRONI, Paulo. Novíssimo dicionário de economia. Editora Best Seller, 1999.

STAL, Eva; NOHARA, Jouliana Jordan; DE FREITAS CHAGAS JR, Milton. Os conceitos da inovação aberta e o desempenho de empresas brasileiras inovadoras. Revista de Administração e Inovação, v. 11, n. 2, p. 295-320, 2014.

TEECE, David J. "Profiting from technological innovation: Implications for integration, collaboration, licensing and public policy”. Research policy, v. 15, n. 6, p. 285-305, 1986.

VANHAVERBEKE, Wim; VAN DE VRANDE, Vareska; CHESBROUGH, Henry. "Understanding the advantages of open innovation practices in corporate venturing in terms of real options”. Creativity and innovation management, v. 17, n. 4, p. 251258, 2008.

VON HIPPEL, Eric. "The dominant role of users in the scientific instrument innovation process”. Research policy, v. 5, n. 3, p. 212-239, 1976.

WEST, Joel et al. “Open innovation: The next decade”. Research Policy, v. 43, n. 5, p. 805-811, 2014. 